\title{
obituary
}

\section{Sverre Fehn:}

\section{Ranald Lawrence}

Sverre Fehn has died at the age of 84 . His work defied easy categorisation yet remained stubbornly relevant, subverting a contemporary international scene of skin, events and situation in architecture. Admired at home, yet for long almost unheard of abroad, his office was frequently awarded first prize in architectural competitions in Norway but many of his projects remained unbuilt - considered too difficult and expensive to realise. The work that was built stands as testament to Fehn's deep understanding both of the present condition of architecture and of Norway, and its significance was eventually recognised with the award of the Pritzker Architecture Prize in 1997.

Fehn graduated in the second cohort from the new architecture school in Oslo in 1949, tutored by Knut Knutsen and Arne Korsmo. He first came into contact with CIAM through Jørn Utzon, Aldo Van Eyck and Alison and Peter Smithson, but could not afford the expense of travelling to the meetings. He was, however, awarded a scholarship to study in Paris under the guidance of Jean Prouvé, where he would go and watch Le Corbusier working in his studio when it was opened up to students in the evening.

The origins of Fehn's architecture are clear also from where he chose to live. He bought and lived for the rest of his life in Villa Damman, constructed just after the Stockholm Exhibition of 1930 by his old tutor Arne Korsmo, a typical example of a Modernist house of that era. In 1952, he married Ingrid Loberg Pettersen, and together with close friends Norberg-Schulz, Grung, Vesterlid and Jørn Utzon, founded PAGON (Progressive Architects Group Oslo Norway), the

\section{the architect who built on the horizon}

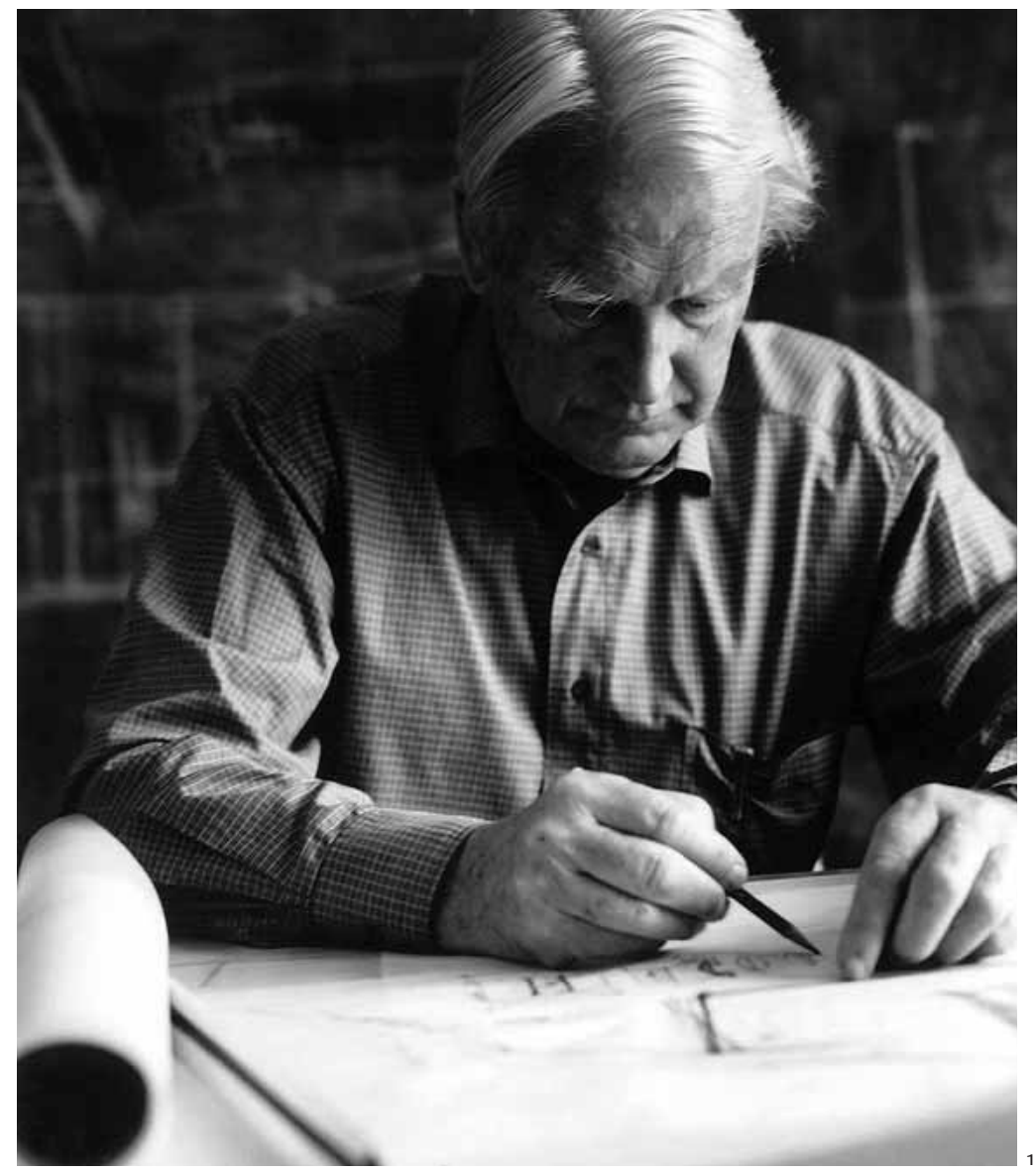

Sverre Fehn

Norwegian branch of CIAM. His first completed building, a craft museum at Maihaugen (1953), was realised in close collaboration with Geir Grung (1926-89), with whom he also designed the Økern Home for the Elderly, completed in 1955. In 1971 he was awarded a professorship at his old school, the Oslo School of Architecture and Design, where he taught and inspired the next generations until his retirement in 1995.

In Le Corbusier's architecture, and later in the vernacular houses of Morocco, Fehn appreciated a formal purity, honesty and simplicity that suggested a way of reuniting architecture with human experience, time and shadow. Fehn's observations made him susceptible to an analysis that is entirely contemporary, and he is still often quoted by architects and critics alike. Above the earth and below the sky, for Fehn the horizon, the space between (in Norwegian, Mellomrom), was metaphorically the realm of man. According to Gennaro Postiglione, he 'attempted 


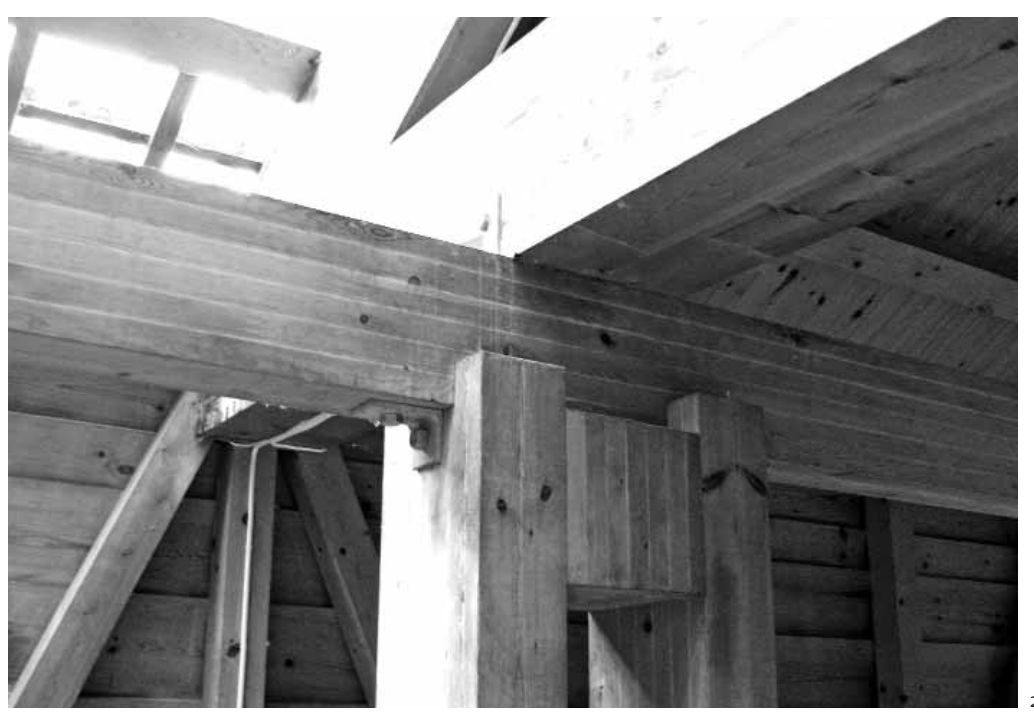

The structure brought to the light, Hedmark Cathedral Museum, Hamar (1979)

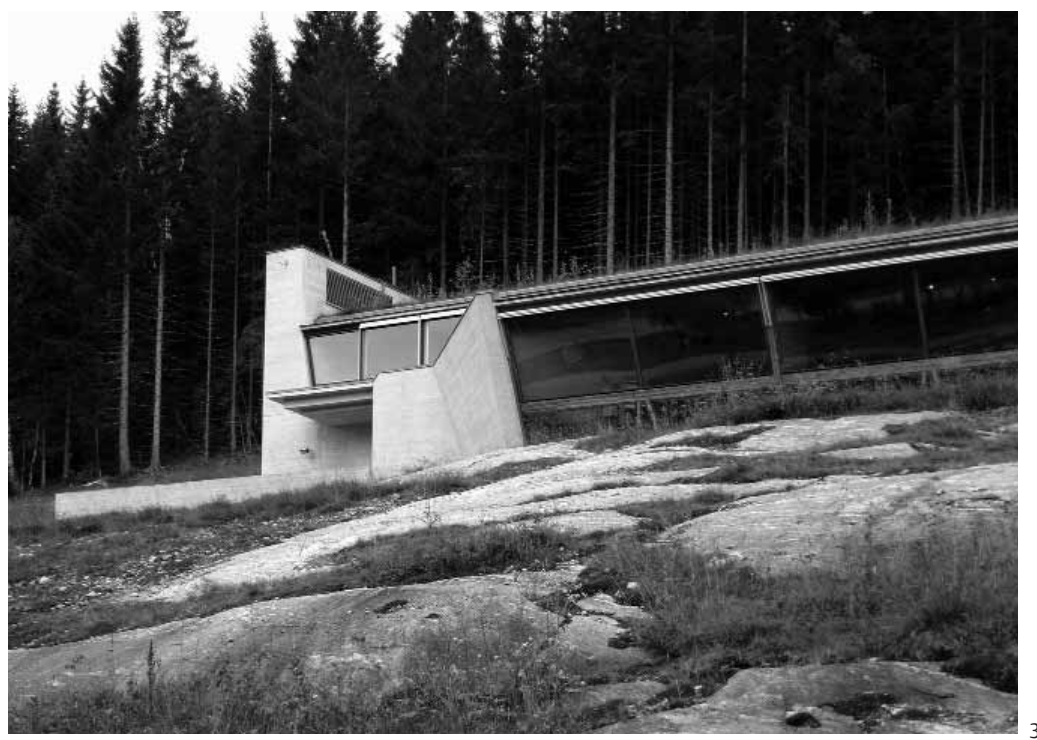

Building rooted to the ground: the Ivar Aasen Centre (2000)

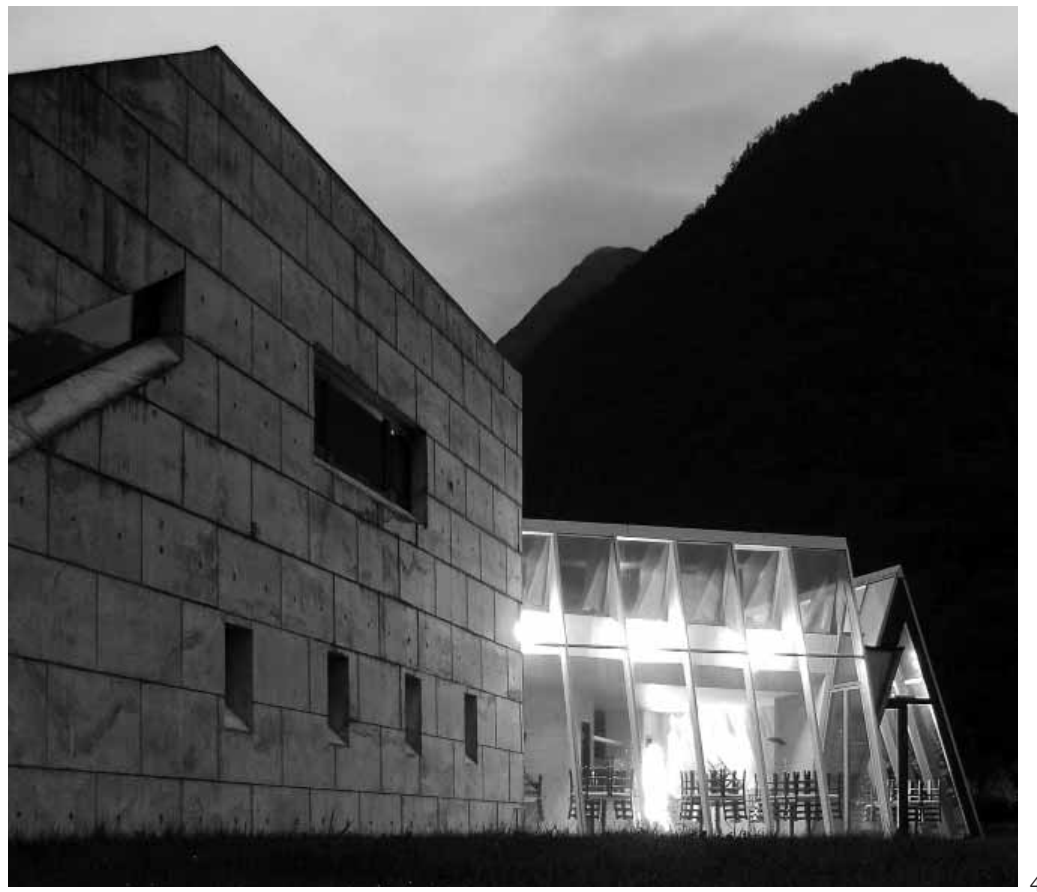

The construction as a microcosm of the site: the Glacier Museum, Fjærland (1991)

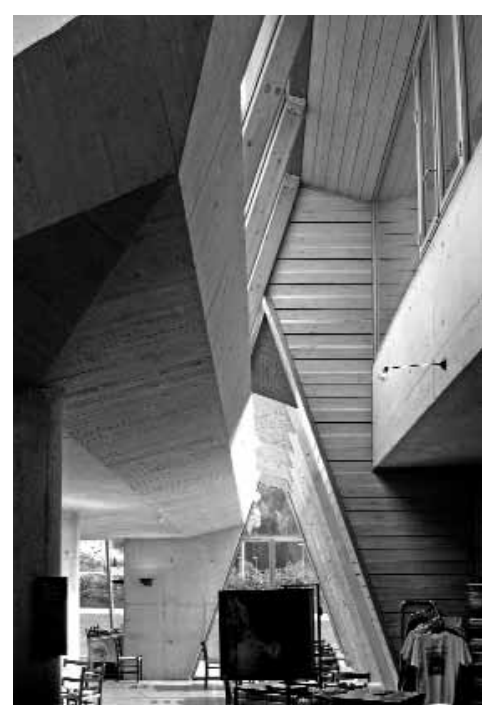

The mass is carved away by the light

to provide "a horizon for man", so that each project might identify a place in space between earth and sky'. ${ }^{1}$ One of his favourite stories involved walking in the Norwegian landscape:

Within himself, every man is an architect. His first step towards architecture is his walk through nature. He cuts a path like writing on the surface of the earth. The crushing of grass and brushwood is an interference with nature, a simple definition of man's culture. His path is a sign to follow. ${ }^{2}$

Fehn was interested in tectonic expression [2], but above all he was a topographic architect [3]. The first question he asked of any site was where to build. Villa Busk in Bamble, completed in 1990, is situated partly in a disused quarry, and is an example of a walk in the landscape to find a spot to build, mediating between the journey to town and work outside the front door and the journey to the pier and fjord (nature) through the back. The Glacier Museum at Fjærland (1991) elementally carries the visitor up to the glacier [4] and the glacier down to the visitor [5]. At perhaps his finest work, the Hedmark Cathedral Museum in Hamar (1979), the path the visitor takes is literally a sign to follow $[6,7,8]$.

At Hamar the visitor rises up, and is guided effortlessly among the exhibits. In the main space inside the barn, Fehn created concrete boxes held above the excavations below and accessed from a horizontal walkway [9]. The barn is lit only where light filters in through the openings between the ruins and the new roof, but inside the concrete boxes the roof above is glazed to flood the exhibits with daylight. The visitor's imagination 

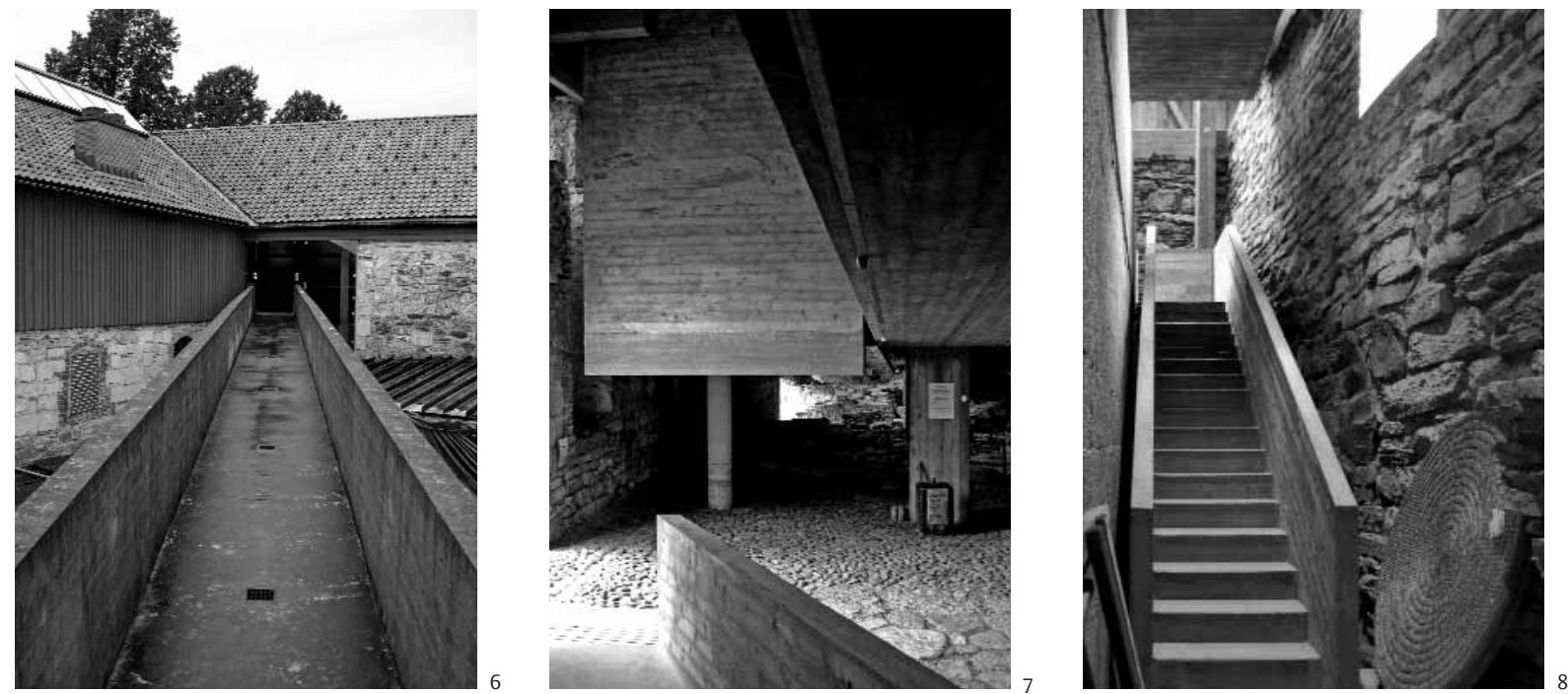

Paths to follow, Hamar
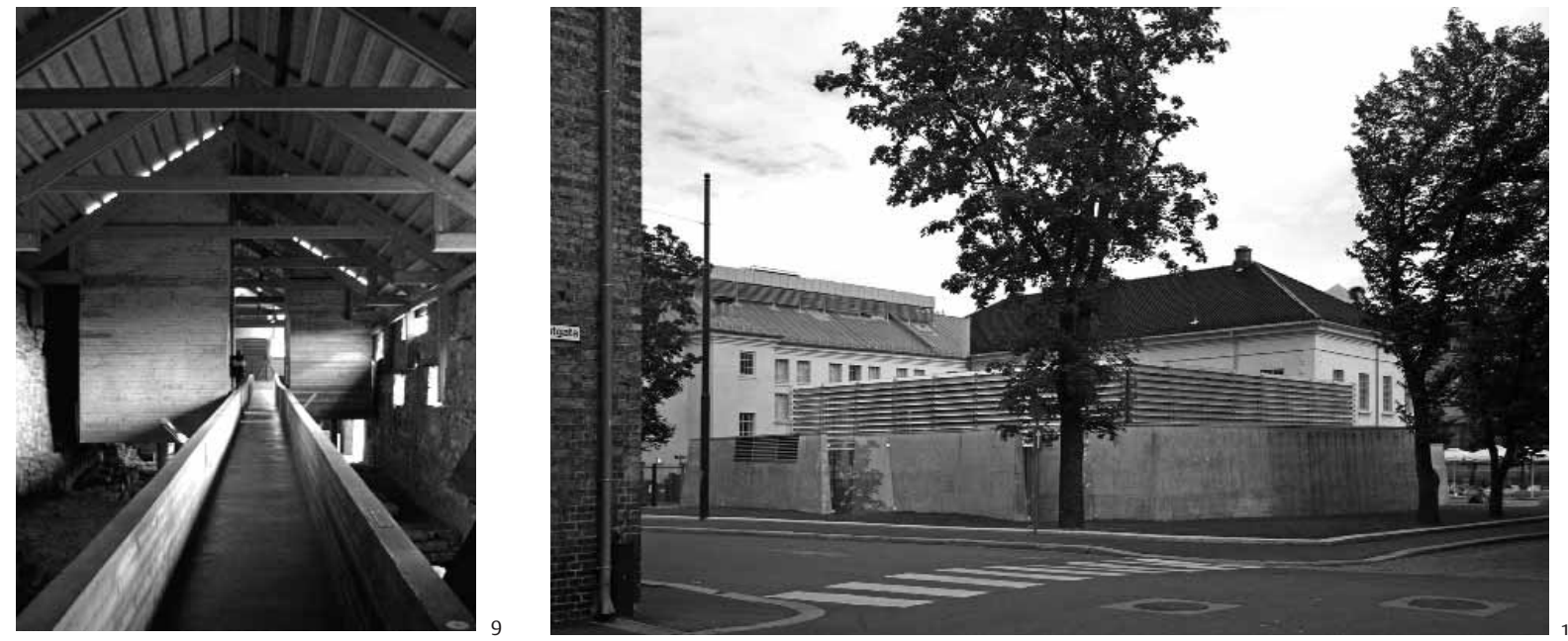

The museum is suspended over the past

The artificial horizon, Museum of Architecture, Oslo

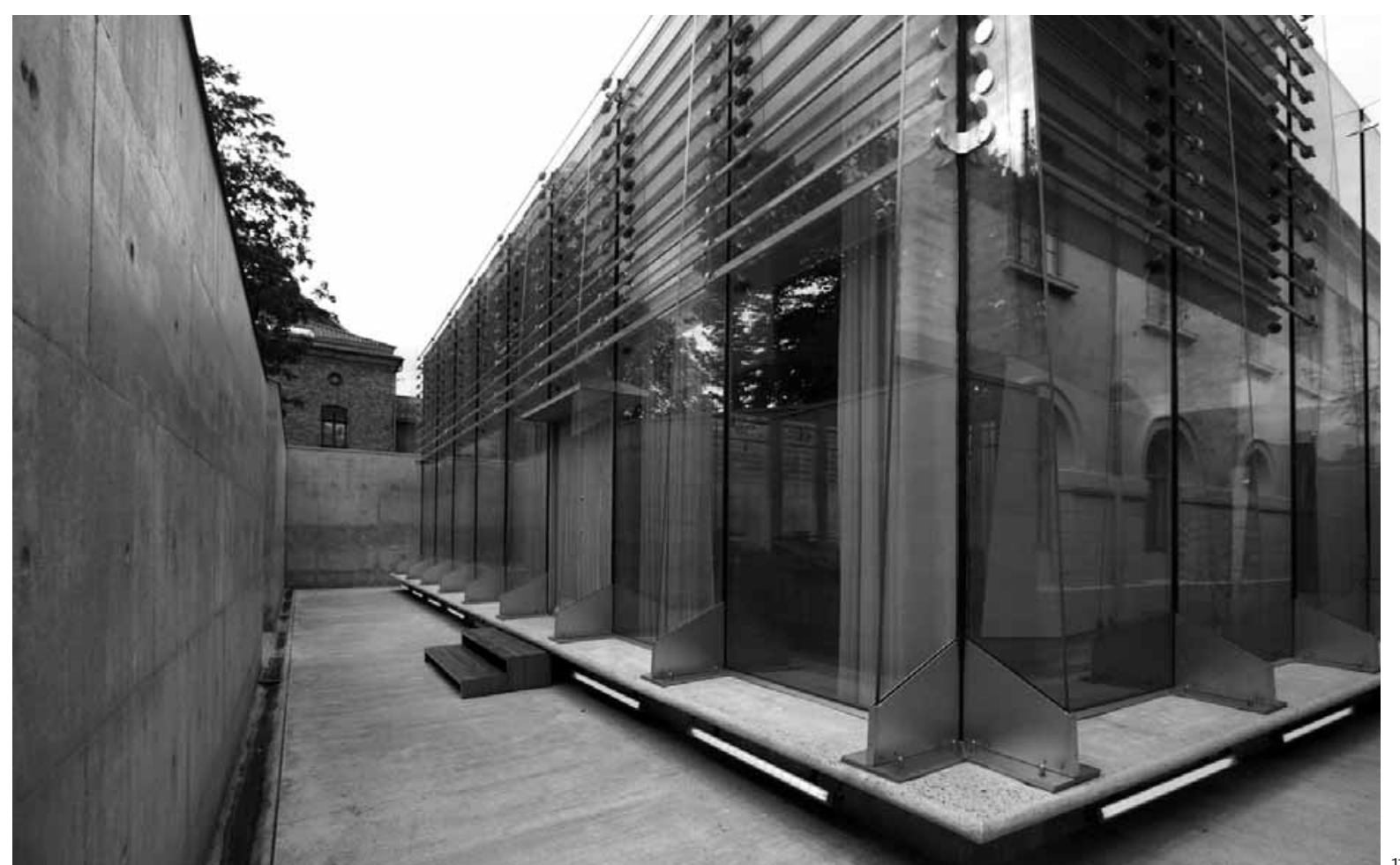




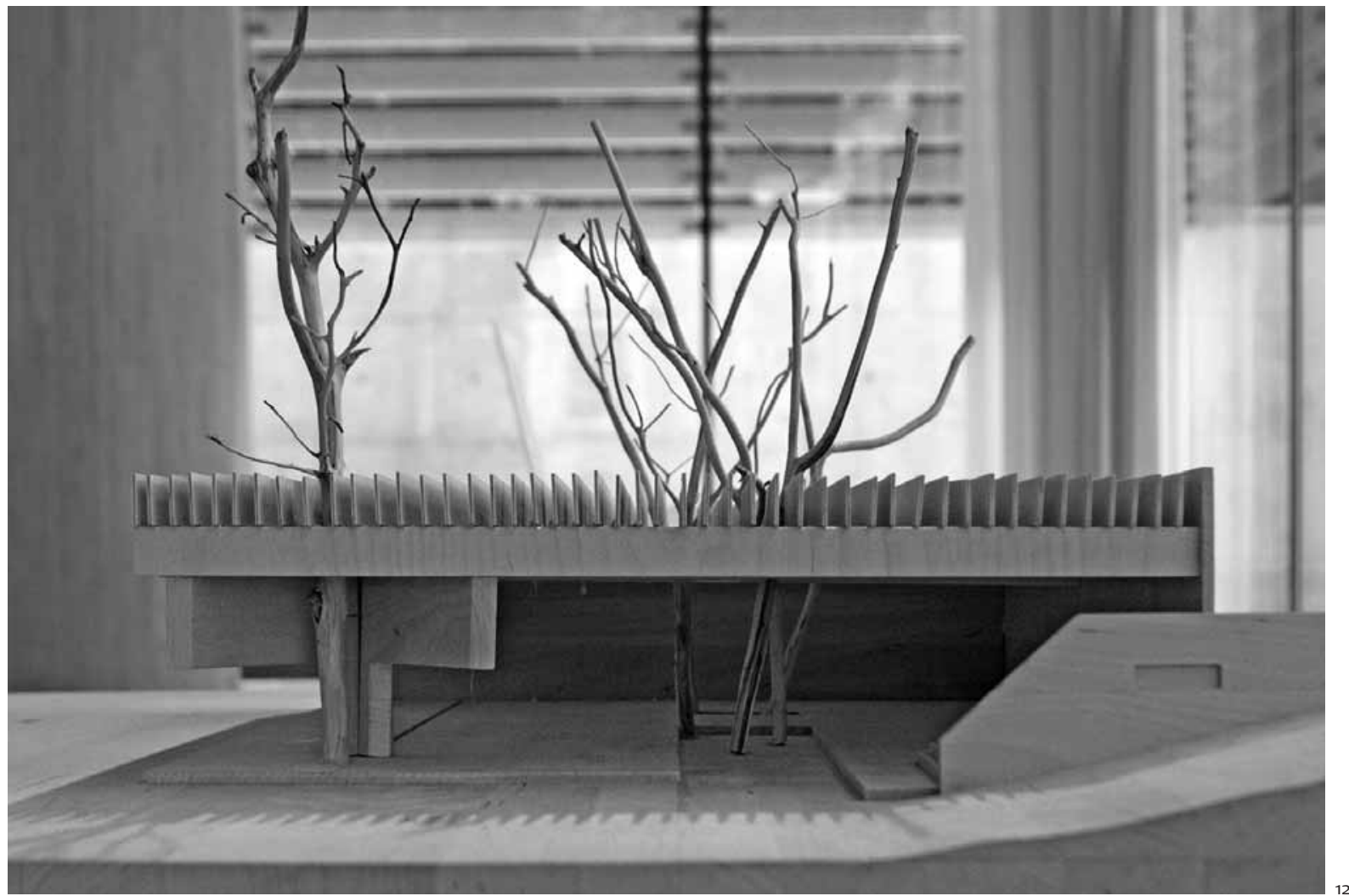

A model of the Venice Pavilion (1969) inside the Oslo Pavilion: the interior as an overcast sky

is allowed to calmly wander, interrupted sporadically and briefly with the clarity of a fact of the past. 'It is possible to be in a position to understand history not with the aid of pages of a bookbut as it appears in the world of archaeology. ${ }^{3}$ The artificial horizon line of the eaves of the roof is set in relationship to the line of the top of the ruins, but

furthermore, by the skilful use of vertical formwork in the columns that hold the concrete boxes and ramps, Fehn creates the plumb line that measures the construction of the present to the fragmented past below. He reflected that:

The past is suddenly present, the stones come close to you, the ruins look more material and more real, because they make up a story at the same time as they are attacked. I am sick of the sentimental way of dealing with these matters. On the other hand, if you look at my (other) buildings and their surroundings, you can easily see that I have tried to preserve every single tree. It is a love-hate story. ${ }^{4}$ A recently completed building that continues this dialogue with place is Fehn's extension to the Museum of Architecture in Oslo [10]. He has created a new pavilion joined to $C$. H. Grolsch's Bank of Norway from 1830, which has been converted to an archive centre. While this is an urban site, and the walls of the pavilion are entirely glazed, a concrete wall placed two and a half

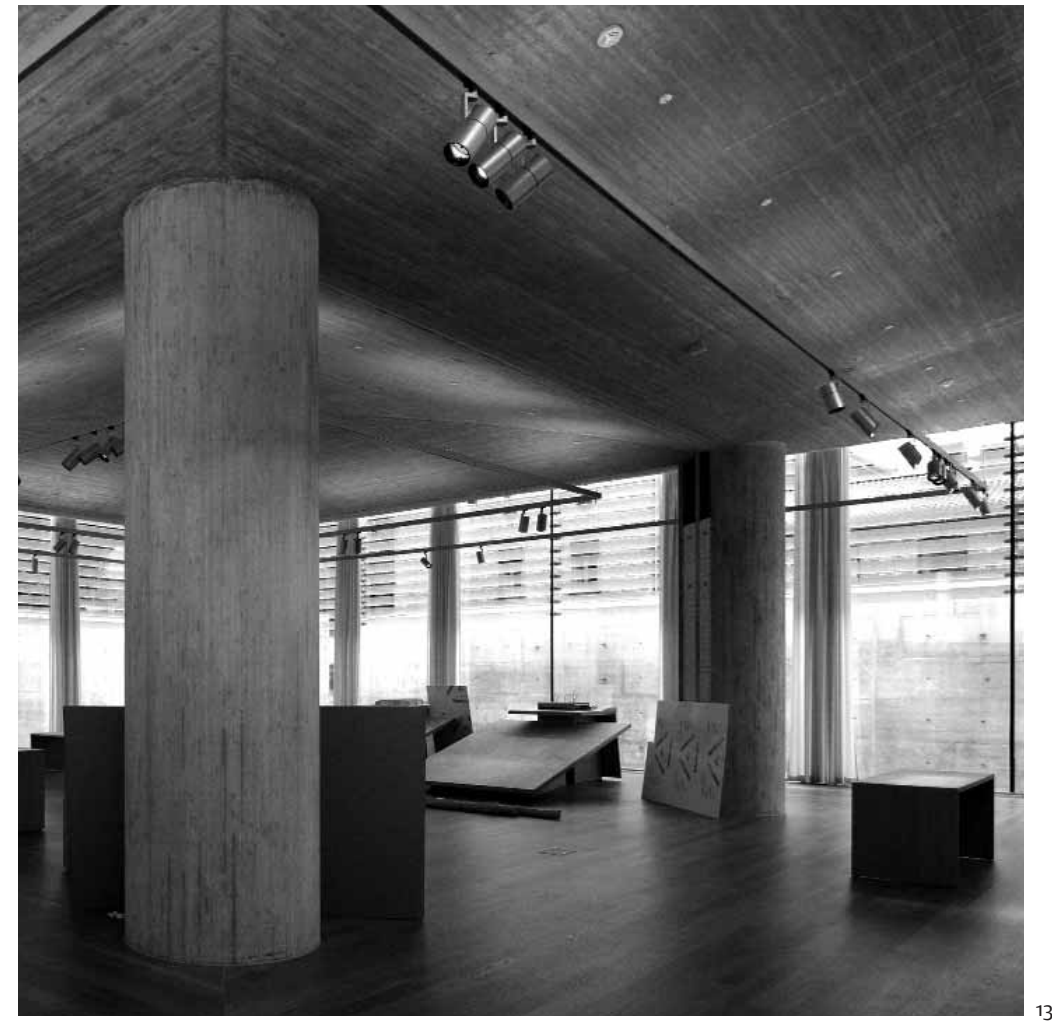

The concrete sky of the Oslo Pavilion

metres outside the glass defines a horizon that limits the visible outside world [11]. Here Fehn is at home: the Norwegian light is a present fact and requires no invention as at his renowned Nordic Pavilion in Venice [12]. A vaulted concrete roof [13] is supported on four columns centred on the square plan, while the floor is finished in polished wood. Walking across the square, underneath the centre of the vault, a clap of thunder is generated that is focused back solely on the individual in the centre of the space. 


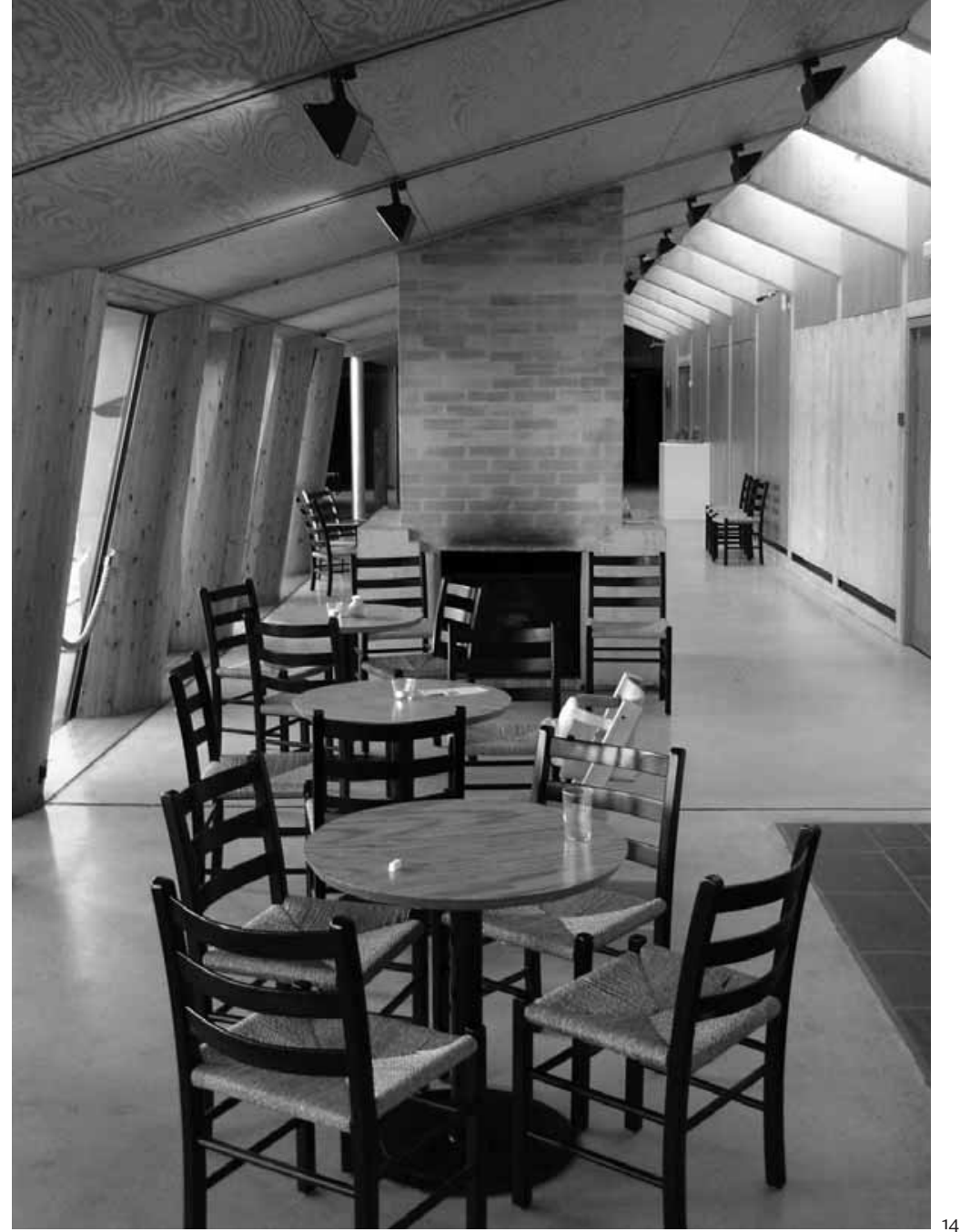

The hearth of the Kjell Aukrust Centre (1996): a timeless gathering place

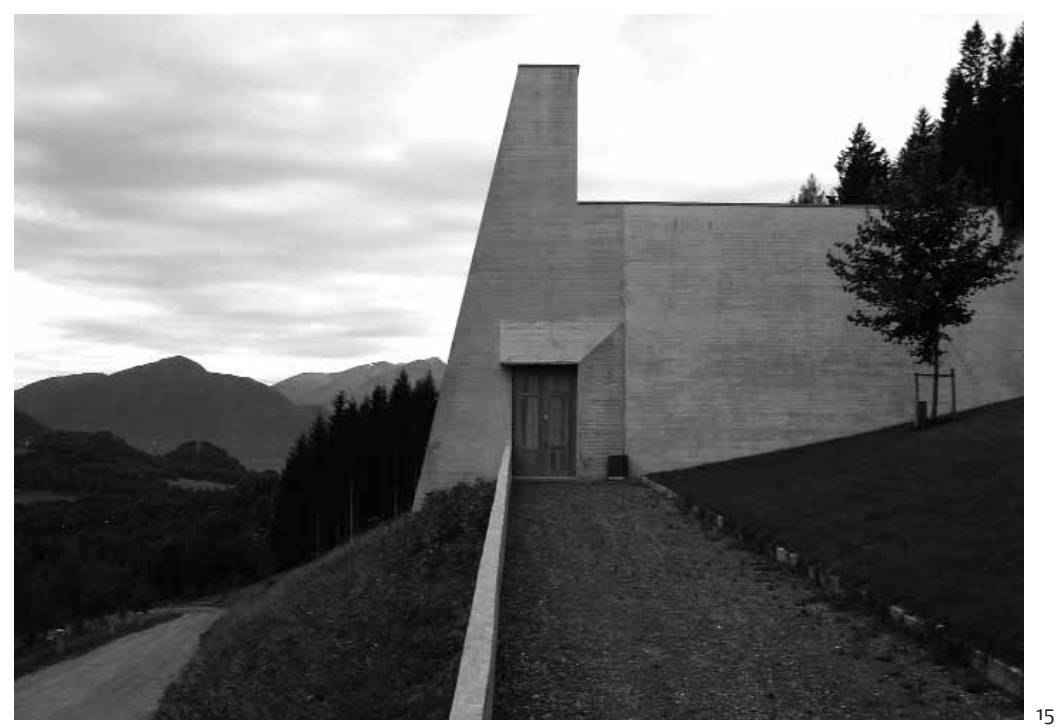

The Ivar Aasen Centre: a journey of the spirit

As soon as we define an interior and exterior, it evokes a memory of the human body; in Cartesian terms our sense of self is internal and everything else is external. Fehn's centring of the sound in this space gives rise to a harmonious connection between the individual and the wider world: insomuch as sound (oral tradition) is the first embodiment of human culture, it relocates man at the centre of his universe.

This final work is a fitting tribute to Sverre Fehn the architect and thinker, who understood that buildings can only be experienced and understood by individuals, was nostalgic for a time when architecture had its place in culture without the need to search for a place in history, who expressed a 'profound unease with the spiritual and cultural consequences of modern technology' [14], ${ }^{5}$ but who ultimately found fulfilment in the fact that 'if you look at the material in the dimension of time, walls belong to history, the tree is fleeting and belongs to eternity' [15]. ${ }^{6}$

Sverre Fehn was born in Kongsberg, Norway on 14 August 1924, and died in Oslo on 23 February 2009, aged 84. He is survived by his son and four grandchildren.

Ranald Lawrence is studying for an MPhil in Environmental Design in Architecture at Cambridge University, and is author of 'Building on the Horizon: The Architecture of Sverre Fehn', published in ptah in 2007.

\section{Notes}

1. Christian Norberg-Schulz, and Gennaro Postiglione, Sverre Fehn: Works, Projects, Writings, 1949-1996, translated from Italian by Alessio Assonitis (New York: The Monacelli Press, 1997), p. 53.

2. Sverre Fehn, Pritzker Prize Acceptance Speech, Bilbao, 31 May 1997.

3. Sverre Fehn, The Poetry of the Straight Line, translated by Joan Tate (Helsinki: Museum of Finnish Architecture, 1992), p. 17.

4. Ibid., p. 48.

5. Per Olaf Fjeld, Sverre Fehn, The Thought of Construction (New York: Rizzoli International Publications, 1983) p. 15 .

6. Fehn, The Poetry of the Straight Line, p. 34 .

\section{Illustration credit}

arq gratefully acknowledges:

Author, all images 